\section{Arrependimento após a esterilização feminina no Brasil}

\section{Regret subsequent to sterilization among Brazilian women}

Luciana Freitas Barbosa 1

lúri da Costa Leite 2

Marina Ferreira de Noronha 3

\begin{abstract}
Objectives: to identify socio-demographic factors associated with regret following sterilization.

Methods: a cross-cutting study was carried out using data from the National Population and Health Survey conducted in Brazil in 1996. The sample comprised 3233 women of child-bearing age who had been sterilized at least one year prior to the interview. The logistic regression model was employed.

Results: the proportion of women regretting sterilization was $10.5 \%$ and the main reason reported was the desire to have another child (62.7\%). The likelihood of a sterilized woman aged 35 years or over regretting sterilization was less than that for women aged below 25 years $(p<0.01)$. Women with more than nine years of schooling are less likely to regret sterilization than women with three years of schooling or less $(R C=0.75$; 95\%CI: 0.51-1.03).

Conclusions: young women with a low level of education are the group that is most likely to have regrets following sterilization. These results may aid family planning program managers, restating the need for orientation regarding the irreversibility of the method and the changes that may occur in the lives of women in the course of the reproductive cycle, thereby minimizing the possibility of a woman coming to regret the decision.
\end{abstract}

Key words Sterilization, Sterilization, tubal, Brazil
1-3 Escola Nacional de Saúde Pública. Fundação Oswaldo Cruz Rua Leopoldo Bulhões, 1.480, sala 726. Rio de Janeiro, RJ, Brasil. CEP: 21.041-210. E-mail: lu.freitas@superig.com.br

\section{Resumo}

Objetivos: identificar fatores sócio-demográficos associados com o arrependimento após a esterilização.

Métodos: trata-se de um estudo de corte transversal com dados da Pesquisa Nacional de Demografia e Saúde realizada no Brasil em 1996. A amostra é composta por 3233 mulheres em idade reprodutiva, cuja esterilização ocorreu há pelo menos um ano antes da entrevista. Um modelo de regressão logística foi utilizado.

Resultados: a proporção de mulheres arrependidas foi de $10,5 \%$ e a principal razão relatada foi $o$ desejo de ter outro filho $(62,7 \%)$. A chance de uma mulher esterilizada com 35 anos ou mais se arrepender é 69\% menor que uma mulher com menos de 25 anos $(p<0,01)$. Mulheres com nove anos ou mais de escolaridade são menos propensas de se arrepender do que mulheres com três anos ou menos ( $R C=0,75$; IC95\%: 0,51-1,03).

Conclusões: mulheres jovens e de baixa escolaridade constituem um grupo com chance elevada de arrependimento após a esterilização. Os resultados podem subsidiar gestores de programas de planejamento familiar, reforçando a necessidade de orientações quanto à irreversibilidade do método e às mudanças que podem ocorrer na vida das mulheres durante o ciclo reprodutivo, minimizando a chance de arrependimento.

Palavras-chave Esterilização, Esterilização tubária, Brasil 


\section{Introdução}

A esterilização feminina tem sido considerada o método de contracepção mais utilizado no mundo. ${ }^{1}$ Segundo levantamento feito pelas Nações Unidas, ${ }^{2}$ $21 \%$ de todos os casais adotaram a esterilização feminina como opção contraceptiva. O segundo método mais utilizado é o DIU, 14\%, seguido pela pílula, utilizada por $7 \%$ das mulheres casadas ou em união consensual. No Brasil, a elevada prevalência da esterilização feminina tem sido apontada como um elemento importante no declínio da fecundidade no país, que passou de 6,2 filhos em 1960 para 2,1 em 2003.3,4 Segundo a última pesquisa de base populacional realizada no Brasil, a Pesquisa Nacional de Demografia e Saúde (PNDS), em 1996,5 a esterilização feminina é o método mais prevalente aqui, com aproximadamente $40 \%$ das mulheres casadas ou em união consensual de 15 a 49 anos esterilizadas. Neste contexto, o Brasil situa-se na terceira posição entre os países com maior prevalência de esterilização no mundo.

Os fatores que estão associados à utilização da esterilização em nosso país são múltiplos: falta de acesso e/ou informação acerca dos métodos contraceptivos reversíveis, precariedade dos serviços de planejamento familiar, percepção da esterilização como forma de ascensão social, uma cultura baseada na desresponsabilização masculina em relação à contracepção, entre outros.6,7 Esses fatores, aliados a alta eficácia atribuída ao método, têm contribuído para a elevada prevalência de mulheres esterilizadas observada no Brasil. 8

Uma das consequências da esterilização pode ser o arrependimento, conceito subjetivo que, inclusive, pode mudar ao longo do tempo. Entende-se o arrependimento após a esterilização como uma mudança em relação à decisão de encerrar a vida reprodutiva. Em se tratando de métodos contraceptivos reversíveis, há a possibilidade de interrupção do uso, o que é mais difícil no caso da esterilização cirúrgica. Três definições têm sido utilizadas para caracterizar o arrependimento: mulheres que se autodeclararam arrependidas; aquelas que procuraram por informações sobre a reversão da esterilização; e mulheres que, de fato, solicitaram a cirurgia para reversão. 9,10

Nos Estados Unidos, verificou-se que a incidência acumulada em cinco anos da mulher se arrepender da realização da esterilização é de $7,0 \% .{ }^{11} \mathrm{Na}$ Índia, em pesquisa realizada em quatro Estados, a incidência do arrependimento situou-se entre 4,3\% e 9,6\%.12 Na República Dominicana, em estudo transversal, a proporção de mulheres arrepen- didas foi de $16 \% .13$

O arrependimento ainda é um tema pouco explorado no Brasil. Segundo estudos realizados em algumas cidades do país, a taxa de arrependimento encontrada variou de $11 \%$ a $15 \% .{ }^{14-16}$ Segundo a PNDS-1996, única pesquisa de âmbito nacional que aborda o assunto, a taxa de arrependimento foi de $10,5 \%$.

Estudos mostraram que a morte de filhos, novo casamento, idade da mulher no momento da esterilização, problemas conjugais, pouco conhecimento sobre os métodos reversíveis e escolha do método sob pressão do companheiro são fatores ligados ao arrependimento. 10,11,17,18 Dos fatores citados, a associação mais importante é entre a idade da mulher no momento da esterilização e a probabilidade de arrependimento posterior, como evidenciaram Curtis et al. ${ }^{1}$ por meio de revisão sistemática de literatura.

Outro fator que pode contribuir para o arrependimento é a falta de informações adequadas acerca da irreversibilidade do procedimento. Em pesquisas realizadas nos Estados de São Paulo e Rio de Janeiro, constatou-se que um percentual considerável de mulheres não tinha conhecimento sobre o caráter definitivo da cirurgia.19-21

Quanto às possibilidades de reversão da esterilização feminina, trata-se de uma cirurgia custosa, difícil e com poucas chances de ser bem sucedida. Fernandes et al.22 observaram uma taxa bastante pequena de sucesso. Portanto, cabe envidar esforços para qualificar as orientações antes das cirurgias de esterilização, buscando evitar o arrependimento posterior.

O objetivo do presente estudo é identificar os fatores sócio-demográficos associados com o arrependimento após a esterilização, utilizando-se uma base de dados com representatividade nacional: a PNDS-1996. Acredita-se que esse estudo pode ser de grande importância para os formuladores de políticas públicas, tendo em vista a elevada prevalência de mulheres esterilizadas no Brasil e a atual legislação que regulamentou a realização de laqueadura tubária no país. Além disso, a despeito de ter sido realizada há aproximadamente 10 anos e ter proporcionado uma grande variedade de estudos sobre a esterilização feminina, nenhuma análise sobre arrependimento foi encontrada, até o momento de realização desse artigo, utilizando a referida pesquisa.

\section{Métodos}

Trata-se de um estudo de corte transversal, utilizando como fonte os dados da Pesquisa Nacional 
sobre Demografia e Saúde realizada em 1996 (PNDS - 1996), pela Sociedade Civil de Bem-Estar Familiar no Brasil (BEMFAM), com apoio técnico da Macro International Corporation, como parte do programa mundial de Pesquisas de Demografia e Saúde (Demographic and Health Surveys - DHS). A amostra da PNDS-1996 é uma subamostra da Pesquisa Nacional por Amostra de Domicílios (PNAD) realizada pelo Instituto Brasileiro de Geografia e Estatística (IBGE) em 1995 (PNAD-95), desenhada para obter resultados representativos para as regiões do país e alguns estados. Nessa pesquisa foram coletadas informações sobre os níveis da fecundidade, saúde, mortalidade infantil e materna, anticoncepção, saúde da mulher e da criança, conhecimento e atitudes relacionadas às doenças sexualmente transmissíveis (DST/AIDS), além de características sócio-demográficas da população entrevistada. 5

Na PNDS-1996 foram realizadas 12.612 entrevistas com mulheres de 15 a 49 anos, das quais 3447 realizaram a esterilização cirúrgica. No questionário da PNDS-1996 há uma pergunta sobre arrependimento "Você se arrepende de ter feito essa operação?" e outra sobre as razões pelas quais essas mulheres se arrependeram. Há também uma pergunta sobre a insatisfação com o método "Do seu ponto de vista, hoje, está satisfeita com sua decisão de fazer a operação?" De forma semelhante, as mulheres que reportaram a insatisfação com a decisão, também foram inquiridas sobre a razão pela qual estavam insatisfeitas. No presente estudo as mulheres que se declararam insatisfeitas não foram consideradas como arrependidas, pois assume-se que esses dois conceitos são diferentes. Todas as observações de mulheres cuja esterilização ocorreu há menos de um ano da data da entrevista foram excluídas como forma de dar tempo suficiente para que a mulher se adaptasse à cirurgia. 15

A variável resposta foi o arrependimento após a esterilização, onde o valor 1 indica que a mulher se declarou arrependida de ter feito a esterilização. A identificação dos fatores associados ao arrependimento após a esterilização foi realizada utilizando o modelo logístico. 23

A análise desenvolveu-se em dois estágios. No primeiro, o efeito de cada variável foi mensurado, controlando-se apenas pela variável tempo entre o nascimento do filho mais jovem e a data da esterilização. Nessa análise, denominada não-ajustada, em função de não se estar levando em conta outros fatores, todas as variáveis significativas ao nível de $25 \%(p \leq 0,25)$ são selecionadas. No segundo estágio, o modelo ajustado é implementado e as variáveis estatisticamente significativas ao nível de 5\% são interpretadas. A seleção das variáveis foi feita por meio dos testes de Wald e da Razão de verossimilhança. $\mathrm{O}$ ajuste do modelo foi avaliado pela estatística $\Delta \beta$ que mede a variação nos coeficientes dos parâmetros quando uma observação específica é excluída. ${ }^{24} \mathrm{O}$ software utilizado foi o SAS versão 9.1 .

\section{Resultados}

$\mathrm{Na}$ Tabela 1 estão descritas algumas características das mulheres esterilizadas. A maior parte das mulheres $(57,8 \%)$ realizou a esterilização antes dos 30 anos de idade, era casada $(88,2 \%)$ e tinha dois ou três filhos $(61,4 \%)$. Com relação à raça/cor, 54,2\% se declararam mulatas; $41,7 \%$ brancas e apenas $3,9 \%$ negras.

No que se refere à escolaridade, $30,7 \%$ das mulheres eram analfabetas funcionais (até três anos de estudo); 46,4\% tinham entre quatro e oito anos e apenas $22,9 \%$ tinham nove anos ou mais de estudo. A grande maioria era residente na área urbana $(81,8 \%)$, das regiões Sudeste $(40,5 \%)$ e Nordeste $(29,2 \%)$. Cabe ressaltar aqui, que os autores deste estudo não estão trabalhando com o conceito de risco, ou seja, o fato de termos mais mulheres dessas regiões não implica que a chance de uma mulher se esterilizar seja maior. Indica possivelmente que há mais mulheres nessas áreas. Para se avaliar o risco, seria preciso levar em conta todas as mulheres, esterilizadas e não esterilizadas.

O tempo decorrido entre a esterilização e a entrevista foi de menos de cinco anos para $31,8 \%$ das mulheres e entre cinco e nove anos para $32,9 \%$ delas. Grande parte $(81,6 \%)$ realizou a cirurgia com menos de um ano após o nascimento do filho mais jovem, refletindo o grande número de esterilizações ocorridas concomitante às cesarianas.

Para aproximadamente $16 \%$ das mulheres esterilizadas, a esterilização foi o primeiro método contraceptivo usado. A maioria das mulheres $(73,8 \%)$ utilizou como primeira opção contraceptiva um outro método moderno, sendo a pílula o método mais prevalente. Apenas 10\% das mulheres usaram um método tradicional como primeira opção para evitar a concepção.

Em relação aos motivos informados para decidirem pela esterilização, $36,0 \%$ relatou não querer ter mais filhos. Aproximadamente $26,0 \%$ das mulheres informaram ter realizado a cirurgia por indicação médica. O terceiro motivo mais citado foi a falta de condições financeiras, relatado por $14,3 \%$ 
Tabela 1

Distribuição proporcional das mulheres esterilizadas segundo características selecionadas. Brasil, Pesquisa Nacional de Demografia e Saúde, 1996 (PNDS-1996).

\begin{tabular}{|c|c|c|}
\hline Características & Casos & Proporção \\
\hline \multicolumn{3}{|l|}{ Idade } \\
\hline$<25$ & 707 & 20,5 \\
\hline $25-29$ & 1262 & 36,7 \\
\hline $30-34$ & 962 & 27,9 \\
\hline $35-39$ & 421 & 12,2 \\
\hline $40-44$ & 91 & 2,6 \\
\hline $45-49$ & 4 & 0,1 \\
\hline \multicolumn{3}{|l|}{ Parturição } \\
\hline 0 & 3 & 0,1 \\
\hline 1 & 74 & 2,1 \\
\hline 2 & 932 & 27,0 \\
\hline 3 & 1183 & 34,4 \\
\hline 4 & 553 & 16,0 \\
\hline$\geq 5$ & 702 & 20,4 \\
\hline \multicolumn{3}{|l|}{ Raça/cor } \\
\hline Branca & 1437 & 41,7 \\
\hline Mulata & 1867 & 54,2 \\
\hline Negra & 134 & 3,9 \\
\hline Amarela & 5 & 0,1 \\
\hline Não declarada & 4 & 0,1 \\
\hline \multicolumn{3}{|l|}{ Status marital } \\
\hline Solteira & 22 & 0,6 \\
\hline Casada & 3040 & 88,2 \\
\hline Outros & 385 & 11,2 \\
\hline \multicolumn{3}{|l|}{ Escolaridade } \\
\hline$\leq 3$ anos & 1060 & 30,7 \\
\hline $4-8$ anos & 1598 & 46,4 \\
\hline $9-11$ anos & 598 & 17,4 \\
\hline$\geq 12$ anos & 191 & 5,5 \\
\hline \multicolumn{3}{|l|}{ Área de residência } \\
\hline Rural & 629 & 18,2 \\
\hline Urbana & 2818 & 81,8 \\
\hline \multicolumn{3}{|l|}{ Região } \\
\hline Norte & 201 & 5,8 \\
\hline Nordeste & 1008 & 29,2 \\
\hline Centro-oeste & 406 & 11,8 \\
\hline Sudeste & 1394 & 40,5 \\
\hline Sul & 438 & 12,7 \\
\hline \multicolumn{3}{|c|}{ Tempo entre a esterilização e a entrevista } \\
\hline$<5$ anos & 1097 & 31,8 \\
\hline $5-9$ anos & 1133 & 32,9 \\
\hline $10-14$ anos & 810 & 23,5 \\
\hline$\geq 15$ anos & 407 & 11,8 \\
\hline \multicolumn{3}{|c|}{ Tempo entre o nascimento do filho mais jovem e a esterilização } \\
\hline$<1$ ano & 2813 & 81,7 \\
\hline$\geq 1$ ano & 631 & 18,3 \\
\hline Não declarado & 3 & 0,0 \\
\hline
\end{tabular}


Distribuição proporcional das mulheres esterilizadas segundo características selecionadas. Brasil, Pesquisa Nacional de Demografia e Saúde, 1996 (PNDS-1996).

\begin{tabular}{lcc}
\hline Características & Casos & Proporção \\
\hline Primeiro método utilizado & 554 & 16,1 \\
$\quad$ Esterilização & 2544 & 73,8 \\
Outro método moderno ${ }^{\dagger}$ & 349 & 10,1 \\
Tradicional & & \\
Razão pela qual decidiu pela esterilização & 902 & 26,2 \\
Recomendação médica & 190 & 5,5 \\
Menos efeitos colaterais & 42 & 1,2 \\
Mais fácil de usar & 374 & 10,9 \\
Método definitivo & 1243 & 36,0 \\
Não quer mais filhos & 8 & 0,2 \\
Recomendação de outra pessoa esterilizada & 16 & 0,5 \\
Menos custo & 3 & 0,1 \\
Não teve acesso a métodos reversíveis & 493 & 14,3 \\
Condições financeiras & 176 & 5,1 \\
Outra & & \\
\hline
\end{tabular}

†Os métodos modernos incluem: Pílula, DIU, Injeções, Norplant, Diafragma, Espumas, Tabletes, Condom, Esterilização masculina.

\section{Tabela 2}

Distribuição proporcional das mulheres segundo a razão do arrependimento. Brasil, Pesquisa Nacional de Demografia e Saúde, 1996 (PNDS-1996).

\begin{tabular}{lrr}
\hline Razão & Casos & Proporção \\
\hline Quer outro filho & 228 & 62,6 \\
Marido quer outro filho & 10 & 2,6 \\
Efeitos colaterais & 31 & 8,5 \\
Problemas de saúde associados à operação & 24 & 6,6 \\
Mudou de situação conjugal & 20 & 5,4 \\
O filho morreu & 5 & 1,5 \\
Outra & 33 & 9,0 \\
Não declarada & 14 & 3,8 \\
Total & 365 & 100,0 \\
\hline
\end{tabular}




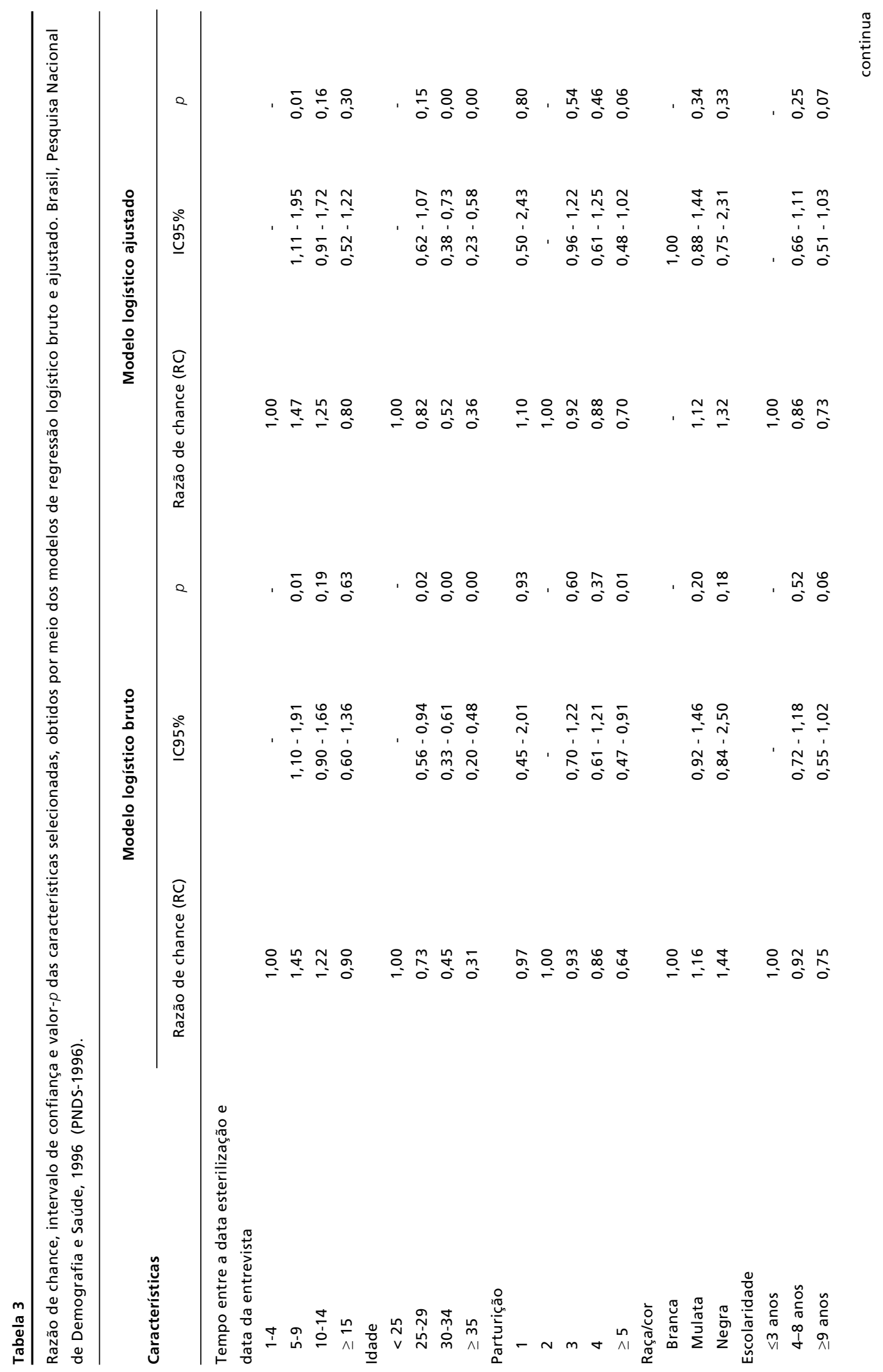




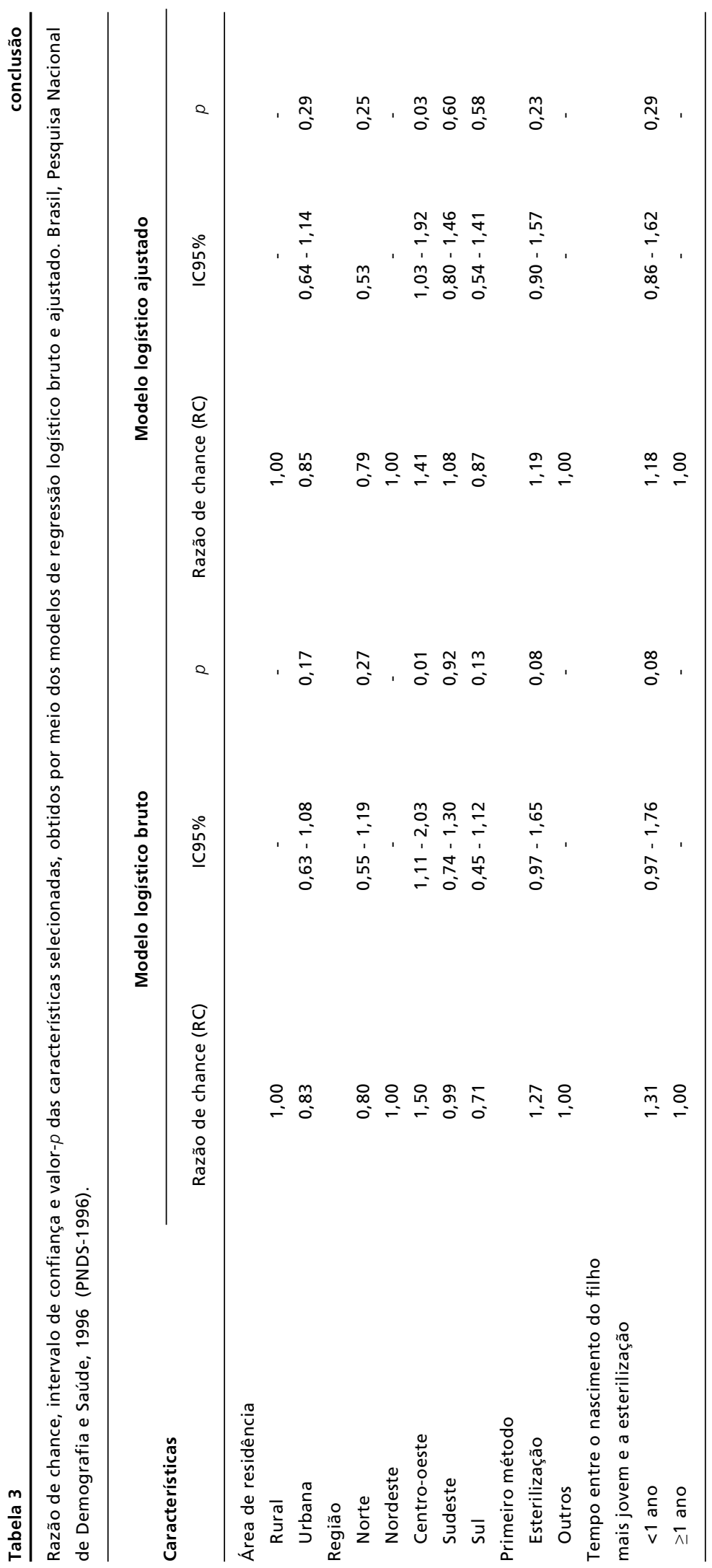


das mulheres.

Quando perguntadas se recomendariam a esterilização, 885 mulheres que fizeram a cirurgia disseram que não, embora deste total, 251 tenham se declarado arrependidas. Entre as mulheres que não recomendariam a cirurgia, 63,2\% (551) apontaram como razão o fato de ser uma decisão íntima e 15,2\% (134) não a recomendariam por tratar-se de procedimento irreversível.

Nesse estudo verificou-se que $10,6 \%$ (365/3447) das mulheres esterilizadas declararam estar arrependidas, sendo a principal razão o desejo de ter outro filho, declarada por $62,7 \%$ das mulheres (Tabela 2). Por outro lado, o principal motivo pela escolha da esterilização como método contraceptivo foi o desejo de não ter mais filhos. Entre os outros motivos citados para o arrependimento destacaramse: problemas de saúde associados à operação $(8,5 \%)$, efeitos colaterais $(6,9 \%)$, marido quer outro filho $(3,3 \%)$, morte do filho $(1,8 \%)$.

Na Tabela 3 são apresentados: razão de chance, intervalo de confiança e nível de significância (valor $p$ ) das variáveis selecionadas, obtidas a partir dos modelos de regressão logístico ajustado e não-ajustado, como possíveis fatores associados com o arrependimento após a esterilização.

A chance de uma mulher se arrepender entre cinco e nove anos após a esterilização é $45 \%$ maior $(\mathrm{RC}=1,45$; IC95\%: 1,10-1,91) quando comparada com a chance de arrependimento entre mulheres que foram esterilizadas há menos de cinco anos. Nas demais categorias, a relação não foi estatisticamente significativa.

A chance de uma mulher esterilizada com idade entre 25 e 29 anos se arrepender é $27 \%$ menor $(\mathrm{RC}=0,73$; IC95\%: 0,56-0,94) do que aquela observada entre mulheres com menos de 25 anos. A chance é 55\% menor ( $\mathrm{RC}=0,45$; IC95\%: 0,33-0,61) entre as mulheres com idade entre 30 e 34 anos e $69 \%$ menor ( $\mathrm{RC}=0,31$; IC95\%: $0,20-0,48$ ) entre aquelas com 35 anos ou mais.

Apenas a categoria formada por mulheres com cinco ou mais filhos mostrou-se associada com o arrependimento. Mulheres com cinco ou mais filhos apresentaram menos propensão para o arrependimento ( $\mathrm{RC}=0,64$; IC95\%: 0,47-0,91).

No modelo ajustado observou-se que a magnitude e significância estatística dos parâmetros são semelhantes às observadas no modelo de regressão logístico não-ajustado. Apesar do parâmetro associado com categoria de mulheres com idade entre 25 e 29 anos no momento da esterilização ter perdido a significância estatística, a direção inversa dessa associação não se modificou. A chance de mulheres com idades entre 30 a 34 e 35 anos ou mais foi respectivamente $48 \%$ e $64 \%$ menor do que aquela observada entre mulheres com menos de 25 anos. A significância estatística do parâmetro associado com a categoria formada por mulheres com cinco filhos ou mais passou a ser limítrofe $(p=0,06)$, mas a razão de chance apresentou pequena alteração, passando de 0,64 para 0,70 .

A chance de uma mulher residente na região Centro-Oeste se arrepender de ter feito a esterilização foi $41 \%$ maior do que aquela observada entre as mulheres da região Nordeste. Por outro lado, mulheres com maior nível de escolaridade (nove anos ou mais) mostraram menor chance de se arrependerem $(\mathrm{RC}=0,73$; IC95\%: 0,51-1,03).

O efeito da variável tempo decorrido entre a esterilização e a data da entrevista sobre o arrependimento praticamente não se alterou. Apenas as mulheres cuja esterilização foi realizada entre cinco e nove anos antes da entrevista apresentaram chance mais elevada de se arrepender em relação às mulheres que foram esterilizadas há menos de cinco $\operatorname{anos}(\mathrm{RC}=1,47$; IC95\%: 1,11-1,95).

\section{Discussão}

O arrependimento após a esterilização cirúrgica é um conceito de difícil definição, pois está vinculado a sentimentos e questões íntimas, que são de difícil caracterização e mensuração. Vieira, 15 em pesquisa realizada em região metropolitana de São Paulo, revelou que $8 \%$ das mulheres, embora não estivessem arrependidas no momento da entrevista, já haviam experimentado o sentimento de arrependimento em algum tempo anterior à entrevista.

Neste estudo verificou-se que a proporção de mulheres que relataram ter se arrependido após a esterilização cirúrgica foi de $10,5 \%$. Contraditoriamente, enquanto o principal motivo que as levou ao arrependimento foi o desejo de ter mais filhos $(62,7 \%)$, para a realização da esterilização foi não querer ter mais filhos. Essa contradição pode revelar a falta de informações ou dificuldades de acesso aos métodos contraceptivos reversíveis antes da realização da cirurgia de esterilização. Pode também reforçar os aspectos ambíguos das escolhas reprodutivas - num determinado momento, a mulher pode estar decidida a encerrar a vida reprodutiva; em momento posterior, pode desejar ter mais filhos. Os resultados do presente estudo corroboram esta hipótese, pois o risco de arrependimento foi maior entre mulheres que realizaram a esterilização entre cinco e nove anos anteriores à entrevista. Não foi observada qualquer diferença significativa em relação ao arrependimento quando comparadas às esterilizações realizadas há mais de 10 anos com 
aquelas realizadas há menos de cinco anos da data da entrevista. Esse resultado não está dissociado da idade da mulher por ocasião da esterilização, que apareceu como um forte preditor, inversamente associado ao arrependimento, pois foram as mais jovens que apresentaram maior chance de arrependimento. Isso pode ser explicado por serem as mais jovens as que ficam mais tempo expostas, durante o ciclo reprodutivo, a mudanças em sua vida que possam resultar em arrependimento. Hardy et al. 18 revelaram que o risco de solicitar a reversão da esterilização para mulheres que fizeram a cirurgia antes dos 25 anos é 18 vezes maior do que para aquelas cuja esterilização foi realizada depois dos 29 anos.

A legislação brasileira ${ }^{25}$ permite a realização da laqueadura tubária em mulheres maiores de 25 anos de idade ou com pelo menos dois filhos vivos, possibilitando às mulheres muito jovens a realização da esterilização. Este encerramento precoce da vida reprodutiva pode aumentar a chance de arrependimento da mulher, conforme evidenciado nesse estudo. Com efeito, esses resultados são importantes para as equipes de saúde que lidam com planejamento familiar, pois há uma demanda bastante significativa pela esterilização entre as mulheres mais jovens. 5 Faz-se necessário orientá-las, principalmente, quanto a irreversibilidade do procedimento, minimizando assim a chance de arrependimento.

Conforme relatado em outros estudos, 11,13 o nível educacional mostrou uma relação inversa com o arrependimento após a esterilização. Quanto maior o nível de escolaridade menor a chance de arrependimento. É provável que essas mulheres estejam mais informadas sobre as características dos métodos contraceptivos, principalmente quanto à irreversibilidade da esterilização, contribuindo assim para um menor arrependimento futuro.

Em relação à região de residência, observou-se elevada propensão ao arrependimento entre mulheres residentes na região Centro-Oeste. É nessa região onde se observa maior chance das mulheres utilizarem a esterilização como método contraceptivo. 26

O fato de grande parte das esterilizações terem sido realizadas há menos de um ano do nascimento do último filho pode estar relacionada às cirurgias de laqueadura tubária realizadas no momento do parto. A indicação do parto cesário para esse fim agrega riscos desnecessários à saúde da mulher e da criança, aumentando o risco de morte e complicações no pósparto. Assim, conforme preconizado pela legislação brasileira, 25 é necessária a dissociação da laqueadura tubária das cesarianas, permitindo à mulher maior espaço de tempo para a reflexão não só sobre o mix de métodos contraceptivos disponíveis, mas também sobre a necessidade ou desejo do encerramento do ciclo reprodutivo. Esses resultados são importantes para subsidiar os gestores do programa de Assistência à Mulher e à Criança (PAISMC).

No Brasil, a prevalência de utilização de métodos contraceptivos é semelhante a dos países desenvolvidos e nossa taxa de fecundidade já está em níveis de reposição. ${ }^{3-5}$ Essa elevada prevalência não significa que as mulheres estejam utilizando os métodos mais adequados ao seu perfil ou que tenham o conhecimento necessário para a sua escolha. As altas taxas de descontinuação de métodos anticoncepcionais em nosso país reforçam esta hipótese. 5 Giffin $^{27}$ caracteriza o processo de controle da fecundidade no Brasil como um caso de "modernidade perversa", pois embora a taxa nacional de uso de métodos seja considerada alta e os métodos usados sejam modernos, a perversidade está nas possibilidades de escolha limitadas pela pobreza.

Ainda que exista uma lei regulamentado o planejamento familiar e estabelecendo critérios e rotinas para a realização das cirurgias de esterilização, tratase de legislação recente e ainda não implementada completamente. 25 Os programas de planejamento familiar deveriam prover uma atenção integral à saúde da mulher, incluindo o acesso a profissionais qualificados, disponibilização de uma variedade de métodos reversíveis, ampliando a possibilidade de escolha da mulher e, assim, contribuindo para o exercício efetivo dos direitos reprodutivos.

\section{Conclusões}

As análises implementadas nesse estudo permitiram a identificação de fatores sócio-demográficos associados com o arrependimento após a esterilização. $\mathrm{Na}$ amostra analisada, com representatividade nacional, verificou-se que a maior parte das esterilizações ocorreu com menos de um ano do nascimento do último filho. Foi de $10,5 \%$ a proporção de mulheres arrependidas após a esterilização e as mulheres jovens e de baixa escolaridade foram as que apresentaram maior chance de se arrepender.

É possível que as mulheres mais jovens não ponderem todos os elementos envolvidos na decisão pela esterilização. Essas mulheres ficam mais tempo do seu ciclo reprodutivo expostas a mudanças em sua vida que podem resultar em arrependimento. Para as mulheres em foco, a ampliação do acesso aos serviços de saúde, com profissionais experientes e capacitados, principalmente nos serviços de aconselhamento, poderia ser o caminho mais rápido e eficaz para a redução das taxas de arrependimento. 


\section{Referências}

1. Curtis KM, Mohllajee AP, Peterson HB. Regret following female sterilization at a young age: a systematic review. Contraception. 2006; 73: 205-10.

2. United Nations. World contraceptive use 2003. [consulted on: 2006 Mar 18]. Available from: http://www.un.org/esa/ population/publications/contraceptive2003/ WallChart_ CP2003.pdf

3. Goldani AM. O regime demográfico brasileiro nos anos 90 : desigualdades, restrições e oportunidades demográficas. In: Galvão L, Díaz J, organizadores. Saúde sexual e reprodutiva no Brasil. São Paulo: Hucitec, Population Council; 1999. p. 25-79.

4. DATASUS. Indicadores e Dados Básicos. Brasil; 2006. [consulted on: 2006 Ago 20]. Vailable from: http://tabnet.datasus.gov.br/cgi/idb2005/a05.htm

5. BENFAM (Sociedade Civil de Bem-Estar Familiar no Brasil). Pesquisa Nacional sobre Demografia e Saúde, 1996. Rio de Janeiro; BENFAM, Macro International; 1997.

6. Villela W, Barbosa R. Opções contraceptivas e vivências da sexualidade: comparação entre mulheres esterilizadas e não esterilizadas em região metropolitana do Sudeste do Brasil. Rev Saúde Pública. 1996; 30: 452-9.

7. Serruya S. Mulheres esterilizadas: submissão e desejo. Belém: Universidade Federal do Pará; 1996.

8. Carvalho MLO, Schor N. Motivos de rejeição aos métodos contraceptivos reversíveis em mulheres esterilizadas. Rev Saúde Pública. 2005; 39: 788-94.

9. Schimidt JE, Hillis SD, Marchbanks PA, Jeng G, Peterson HB. Requesting information about and obtaining reversal after tubal sterilization: findings from the US Collaborative Review of Sterilization. Contraception. 2000; 74: 892-8.

10. Machado KMM, Ludermir AB, Costa AM. Changes in family structure and regret following tubal sterilization. Cad Saúde Pública. 2005; 21: 1768-77.

11. Jamieson DJ, Kaufman SC, Costello C, Hillis SD, Marchbanks PA, Peterson HB. A comparison of women's regret after vasectomy versus tubal sterilization. Obstet Gynecol. 2002; 99: 1073-9.

12. Ramanathan M, Mishra US. Correlates of female sterilization regret in the southern States of India. J Biosoc Sci. 2000; 32: 547-58.

13. Loaiza E. Sterilization regret in the Dominican Republic: looking for quality-of-care-issues. Stud Fam Plan. 1995; 26: 39-48.

14. Vieira EM, Fábio SV, Gueleri W, Picado MP, Yoshinaga E, Souza L. Características dos candidatos à esterilização cirúrgica e os fatores associados ao tipo de procedimento. Cad Saúde Pública. 2005; 21: 1785-91.

Recebido em 11 de fevereiro de 2008

Versão final apresentada em 2 de abril de 2009

Aprovado em 4 de maio de 2009
15. Vieira EM. O arrependimento após a esterilização feminina. Cad Saúde Pública. 1998; 14 (Supl. 1): 59-68.

16. Osis MJD, Faúndes A, Sousa MH, Bailey P. Consequências do uso de métodos anticoncepcionais na vida das mulheres: o caso da laqueadura tubária. Cad Saúde Pública. 1999; 15 : 521-32.

17. Moseman CP, Robinson RD, Bates JRGW, Propst AM. Identifying women who will request sterilization reversal in a military population. Contraception. 2006; 73: 512-5.

18. Hardy E, Bahamondes L, Osis MJ, Costa RG, Faúndes A. Risk factors for tubal sterilization regret, detectable before surgery. Contraception. 1996; 54: 159-63.

19. Vieira EM. A esterilização de mulheres de baixa renda em região metropolitana do Sudeste do Brasil e fatores ligados à sua prevalência. Rev Saúde Pública. 1994; 28: 440-8.

20. Costa SH, Martins IR, Pinto CS, Freitas SRS. A prática de planejamento familiar em mulheres de baixa renda no município do Rio de Janeiro. Cad Saúde Pública. 1989; 5 : 187-206.

21. Vieira EM, Ford NJ. Provision of female sterilization in Ribeirão Preto, São Paulo, Brazil. Cad Saúde Pública. 2004; 20: 1201-10.

22. Fernandes MAS, Arruda MS, Palhares, MAR, Benetti Junior ND, Moreira C M. Seguimento de mulheres laqueadas arrependidas em serviço público de esterilidade conjugal. Rev Bras Ginecol Obstet. 2001; 23: 69-73.

23. Hosmer DW, Lemeshow S. Applied logistic regression. 2. ed. New York: Wiley Interscience; 2000.

24. Allison PD. Logistic regression using the SAS System: theory and application. Cary, NC: SAS Institute Inc; 1999.

25. Brasil. Lei ordinária 9.263, de 12 de janeiro de 1996. Regula o parágrafo 7 do artigo 226 da Constituição Federal, que trata do planejamento familiar, estabelece penalidades e dá outras providências. Diário Oficial da União (DOU) (10): 561-63, 15 jan. 1996. Seção 1. Partes vetadas: Diário Oficial da União (DOU) (159): 17989, 20 ago. 1997. Seção 1. [Acesso em: 2 abr. 2006]. Disponível em: http://www. planalto.gov.br/ccivil/leis/ L9263.htm

26. Tavares LS. Demanda total por anticoncepção no Brasil: uso e necessidade insatisfeita por métodos anticoncepcionais [dissertação]. Rio de Janeiro: Escola Nacional de Saúde Pública; 2006.

27. Giffin K. Pobreza, desigualdade e equidade em saúde: considerações a partir de uma perspectiva de gênero transversal. Cad Saúde Pública. 2002; 18 (Supl.): 103-12. 